\title{
MEMORIAS Y TRANS-FORMACIÓN DE LA IDENTIDAD DE LISETTE EN LA NOVELA ROSALÍA LA INFAME DE ÉVELYNE TROUILLOT
}

\author{
Memories and trans-formation of Lisette's identity \\ in the novel "Rosalia la Infame" by Évelyne Trouillot
}

\section{RESUMEN}

En este artículo se presentará un análisis centrado en las memorias transmitidas a través de los relatos de distintas personajes y en cómo estos resultan ser clave en la evolución experimentada por la protagonista de la novela. El análisis se desarrolla apoyado por diversos recursos teóricos con los que se busca identificar los factores extraídos de dichos relatos orales y en cómo estos afectan la identidad de la protagonista. Al finalizar el análisis se concluye que la evolución o adaptación de la identidad de Lisette deriva en una trans-formación de la misma que responde a una necesidad tanto social como personal de cambio.

Palabras claves: Évelyne Trouillot, Haití, relatos orales, memorias, identidad, trans-formación.

\section{UNIVERSUM}

Revista de Humanidades y Ciencias Sociales

\section{LILIAN SALINAS HERRERA}

Magister en Literatura, mención en Literatura Inglesa y Norteamericana.

Centro de Estudios Avanzados (CEA), Universidad de Playa Ancha Valparaíso, Chile. Correo electrónico: lilian.salinas@upla.cl

Artículo recibido el 13 de febrero de 2019.

Aceptado el 03 de mayo de 2019. 


\section{ABSTRACT}

This article will present an analysis focused on the memories transmitted through the stories of different characters and how they turn out to be key in the evolution experienced by the protagonist of the novel. The analysis is developed supported by various theoretical resources that aim to identify the factors extracted from these oral stories and how they affect the identity of the protagonist. At the end of the analysis it is concluded that the evolution or adaptation of Lisette's identity results in a transformation of it that responds to a social and personal need for change.

Keywords: Évelyne Trouillot, Haiti, oral literature, memory, identity, trans-formation.

\section{INTRODUCCIÓN}

La novela Rosalía la Infame, escrita por la haitiana Évelyne Trouillot fue publicada por primera vez en Francia en el año 2003 bajo el nombre Rosalie l'infâme. Posteriormente, fue traducida al inglés y publicada como The Infamous Rosalie por University of Nebraska Press en el año 2013. Finalmente en el año 2016 la editorial chilena Ambos Editores publicó la versión en español de esta novela bajo el nombre Rosalía la Infame. El premio más importante que se le ha otorgado, corresponde al Prix Soroptimist de la romancière francophone de Grenole del año 2004. Este reconocimiento se entrega por una novela escrita por una mujer francófona con una nacionalidad distinta a la francesa.

Aunque esta novela presenta características de una novela histórica, es importante considerar lo que la autora ha aclarado en el posfacio de la misma, al indicar que no ha querido escribir una novela histórica, aunque se esforzó por respetar el marco histórico.

Inspirada por una historia extraída de Antilles 1789: La Revolution aux Caraibes de Lucien-René Abenon (1789), que daba cuenta de la existencia de una partera arada y el particular simbolismo de un cinturón con nudos 
que ataba a su cintura, la escritora contextualiza la novela en la isla SaintDomingue alrededor del año 1750, en la época previa a la revolución haitiana que derivó en la victoria de los esclavos y en la formación de la primera República Negra, actual Haití, en el año 1804.

La historia es narrada por Lisette, una esclava creol nacida en SaintDomingue quien, a través de conversaciones que sostuvo tanto con su fallecida abuela Charlotte como las que aún comparte con su madrina Ma Agustine, va haciendo propias las memorias tanto de ellas como las de su madre Ayouba y su tía abuela Brigitte, las cuales pasan a ser parte de una herencia oral que paulatinamente va produciendo cambios importantes en la identidad de la protagonista.

Considerando lo anteriormente planteado, aclaro que el análisis se centra en las memorias transmitidas a través de los relatos de distintos personajes y en cómo estos resultan ser clave en la evolución experimentada por la protagonista de la novela cuya identidad deviene otra, trans-formándose. Aclaro que se utilizará trans-formación y no trasnsformación para referirse al proceso de cambio que se evidencia en la protagonista de la novela. Esto basado en la aclaración hecha por la investigadora Daniuska González en el curso de Narrativa Hispanoamericana Contemporánea ${ }^{1}$, según la cual se asume que si bien en el personaje se evidencia una evolución o reformulación de su identidad, esta no corresponde a una transformación común, ya que además de producirse un cambio se debe considerar el hecho de que Lisette se pone en el lugar de sus antepasados, asumiendo como propias las memorias de los hechos que le son transmitidos, dejándose atravesar por estas experiencias al asumirlas como parte de su propia identidad.

Agregado a esto, aclaro que para esta investigación se tomó en cuenta la teoría de Paul Ricoeur en su texto La lectura de un tiempo pasado: memoria y olvido (1999) así como por la postura asumida por Elizabeth Jelin en Los trabajos de la memoria (2001), ya que en ambos trabajos se considera a

\footnotetext{
${ }^{1}$ Perteneciente al programa de Doctorado en Literatura Hispanoamericana Contemporánea de la Universidad de Playa Ancha, Valparaíso- Chile.
} 
las memorias como elementos constitutivos de una nueva identidad tanto individual como colectiva del sujeto.

Sumado a esto la relevancia que la autora otorga a la tradición oral es abordada desde la mirada entregada por Jan Vansina en Tradición oral, historia oral: Logros y Perspectivas (2007), en tanto recuerdos o experiencias transmitidas de boca en boca a futuras generaciones y que en conjunto se transforman en la herencia que es entregada, en este caso, a la protagonista de esta novela.

Al respecto, Tammie Jenkins en la revisión de The Infamous Rosalie para el artículo Haiti: Then and Now (University of Nebraska Press, 2013) señala : "Trouillot uses oral tradition to capture not only the horrors and the indignities of New World enslavement, but also to articulate the daily acts of resistance enacted by slaves..."(Jenkins, s.p.).

Por otro lado, Jean Durosier Desrivières en su artículo para la revista online Collectif 2004 Images: Haiti destaca otro rasgo importante en esta obra y que tiene relación con lo genérico, al centrar las historias más relevantes, así como los relatos de las mismas, en personajes femeninos, tanto por la protagonista como por sus antecesoras. Durosier destaca que la mirada presentada en Rosalía la Infame "nos ofrece la oportunidad de repasar toda una sección de la antigua colonia francesa, a través de otro universo, otra sensibilidad, otro punto de vista, otra mirada: el de las mujeres" (Durosier, 2004 -traducción propia). ${ }^{2}$ También al respecto, Daiana Nascimento dos Santos señala en su reseña para la novela, publicada en la revista Tabuleiro de Letras de junio del 2017 que esta "reivindica el rol protagónico de las mujeres negras/africanodescendientes en las diversas camadas de la sociedad tanto a

2 Así también, la autora de este artículo señaló en la ponencia preparada para el Primer Coloquio Internacional: Los Océanos de Fronteras Invisibles (Universidad de Playa Ancha), titulada "Afro-feminismo y Océanos en Rosalía la Infame de Évelyne Trouillot y El Barco de Ébano de Ricardo Gattini" (2017), que "a lo largo de la narración, podemos percibir la importancia que adquiere la tradición oral como medio de transmisión de las tradiciones y costumbres. Al no existir testimonios escritos, la oralidad se toma como un medio de transmisión valido y de gran significación para aquellos pueblos a los que Hegel se refirió como pueblos sin historia". 
nivel histórico, literario, político, como en cualquier escalón que cumpla en las sociedades" (Nascimento dos Santos, 173).

Así, vemos como en esta novela la protagonista va absorbiendo otras memorias que no pertenecen a su propia biografía y que provocan profundos conflictos internos que derivarán en la alteración de su identidad, transformándola y a la vez preparándola para cumplir con objetivos centrados en los sueños de libertad de sus antecesoras y de toda la población esclavizada. Objetivos que se apropian de Lisette y que producen quiebres importantes, dolorosos pero necesarios para la sobrevivencia y emancipación de un grupo de personas hasta entonces doblegadas pero jamás sometidas.

\section{DE MEMORIAS E IDENTIDAD(ES)}

"No he querido escribir una novela histórica. Que me perdonen, pues algunas digresiones y libertades. Reivindico solamente la humanidad de mis personajes" (Trouillot, 133).

La cita que encabeza este análisis fue escrita por la escritora haitiana Évelyne Trouillot y está incluida en el posfacio de una novela que, más allá de sumergir a los lectores en los horrores de la época de la esclavitud y de la trata negrera, es capaz de brindar un testimonio documentado del contexto histórico en el cual es desarrollada. Porque si bien Trouillot no tuvo intenciones de que Rosalía la Infame (2016), objeto de este estudio, fuese una novela histórica, reconoce haberse esforzado "[...] todo lo necesario para respetar el marco histórico" (Ídem). Siendo así, el contexto de Rosalía la Infame nos sitúa en la isla Saint-Domingue, actual República de Haití a finales del siglo XVIII, época en la cual el miedo de los colonos franceses a ser envenenados por los esclavos rebeldes iba de la mano con el espíritu de rebeldía y sublevación que finalmente llevaría a la Revolución Haitiana y posterior creación de la primera República Negra en el año 1804.

En relación a esto, Sabine Maginat en su artículo La revolución de independencia de Haití en su primera etapa: La edificación del poder negro en Saint-Domingue (2009) explica que previo a dicha revolución, existía por 
parte de los esclavos en la isla "un incesante desafío al sistema esclavista que se manifestaba por conspiraciones, fugas (cimarrones), suicidios y otros, prácticamente desde los orígenes del sistema esclavista de plantación en América" (Maginat, 301). Trouillot incluye este espíritu de rebeldía avivado por las esperanzas de libertad y lo hace sentir a lo largo de toda la novela, en la cual la figura de la resistencia está relacionada con Lisette, una esclava creol de herencia Arada quien se transforma en recipiente de los relatos que la unirán a la historia de resistencia y lucha de sus antecesoras. En este acto de transmisión y rescate, la autora reconoce la importancia que posee la tradición oral en estas comunidades o pueblos ágrafos de personas esclavizadas traídas desde África. Esta forma de transmitir las memorias y conocimientos a través de la oralidad corresponde a lo que Jan Vansina, en su trabajo titulado Tradición oral, historia oral: Logros y Perspectivas (2007) nombra como "tradiciones superficiales informales", las cuales suelen ser conformadas por historias familiares que van atravesando el tiempo, siendo traspasadas de generación en generación (Vansina, 157).

Tomando esto en consideración, se puede apreciar en esta novela como Lisette, a medida que va recibiendo estas memorias relatadas por su única pariente viva, quien es su madrina Ma Agustine, sumadas a los recuerdos de los relatos que le compartió su abuela Charlotte cuando estaba viva, comienza a experimentar pausadamente un proceso de reinvención de su identidad de esclava creol, haciendo propias las vivencias y las historias de su familia, las que gradualmente la integran en la identidad colectiva de los esclavizados africanos.

Rescatar estas memorias del pasado es esencial para formar o transformar la identidad de una persona. Tal como lo menciona Jelin (citando a Pollak) en Los Trabajos de la memoria (2002):

La memoria es un elemento constitutivo del sentimiento de identidad, tanto individual como colectivo, en la medida en que es un factor extremadamente importante del sentimiento de continuidad y de coherencia de una persona o de un 
grupo en su reconstrucción de sí mismo (Jelin, 25).

Mas, el rescate de estas memorias es difícil de ser realizado en lugares donde en el pasado su único o principal medio de comunicación estaba centrado en la oralidad. Al respecto, existe un trabajo realizado por el etnólogo y escritor Amadou Hampâté Bâ quien se dio a la tarea de rescatar las herencias de la tradición oral africana, trabajo que según Teresa Álvarez Martínez es esencial ya que con esto existe una "revalorización de la cultura africana y una manera de dotar a los africanos de unas referencias propias fundamentales para lograr un autoreconocimiento identitario positivo" (Álvarez, 2014). Esta tarea de rescate se asemeja a lo que realizan las mujeres Aradas de la familia de Lisette, quienes a través de los relatos que se le entregan siguiendo una línea matrilineal rescatan sus memorias y a la vez la ayudan en el proceso de trans-formación de su identidad, pasando de ser una esclava creol a reconocerse como una mujer africana Arada.

La trans-formación de la identidad de Lisette va de la mano con un reconocerse en sus orígenes africanos. El autoreconocimiento (identitario) mencionado por Álvarez no sería posible en ella sin los relatos de aquellas memorias que la reubican en África y en sus ancestros. Por ende, su biografía la diferencia de sus antecesoras quienes fueron esclavizadas, ya que ellas eran libres antes de ser secuestradas y forzadas a vivir una vida de esclavitud en Saint-Domingue, a diferencia de Lisette cuyo nacimiento se produjo dentro de la misma isla y no en África, por lo que ella nunca ha sido libre. Al respecto, Daiana Nascimento dos Santos (citando a Herbert Klein) señala que la esclavitud interna en África, la cual se remite a tiempos anteriores a la trata transatlántica, estaba principalmente asociada a un sistema de servidumbre en la que los siervos eran principalmente destinados al servicio doméstico (Nascimento dos Santos, 2015). Posterior a la ya mencionada trata, aquellos que nacían dentro de un sistema de esclavitud en el Nuevo Mundo fueron llamados esclavos, los cuales eran sometidos a limitaciones similares a las que tenían los siervos en África, pero mucho más explotados y violentados. Por consiguiente, Lisette nació como esclava y aunque reconoce las tristezas que 
este hecho conlleva, le resulta difícil concebir la vida de una forma distinta a la que siempre ha conocido. Es en su identidad esclava que Lisette refleja un "sentido de permanencia" o de ser ella misma (Jelin, 24) quedando esto evidenciado en la siguiente cita:

Siendo creol, difícilmente puedo imaginar un ingenio sin blancos, sin amo ni ama. Crecí como la negrita de la niña Sarah, siempre metida en el cuarto de los amos, llevando en mi piel el olor de agua de colonia del ama, los restos de sus polvos en mis dedos y la marca de sus dedos en mi mejilla. Llevo el peso de las manos de su hijo en mi sexo, y el látigo en mí espalda y muslos. La idea de un Saint- Domingue sin niña Sarah, sin el señorito Raoul, me hace titubear y cuando, sin flaquezas, mi mano llena los vasos, me asombro que esta zozobra sólo exista en mi cabeza (57).

Al decir que creció como la negrita de la niña Sara se reconoce claramente la clave de su identidad esclava. Esa es su "mismidad" (Jelin). Ella, como propiedad de alguien más, como un objeto definido por ese sentido de pertenencia a un otro, y que en cierto modo ha aceptado al no conocer ninguna otra realidad.

En el caso de Ma Agustine, su tía abuela Brigitte, su abuela Charlotte y su madre Ayouba existe una gran diferenciación relativa a sus orígenes que las atan a África. Ellas crecieron como mujeres Aradas libres y esa libertad les fue arrebatada violentamente, dejándoles cicatrices tanto físicas como psicológicas que las re-definieron como mujeres esclavizadas en un Nuevo Mundo al cual nunca quisieron ir. Estas heridas deforman sus identidades, y de alguna manera las obligan a rebelarse constantemente en contra de su condición de esclavas. En cambio, en la identidad de Lisette al comienzo de su vida existían vacíos relativos a sus orígenes ancestrales y a la historia de las mujeres Arada por lo que era difícil que se rebelara ante su condición de esclava. Una vez que se instruye gracias a las memorias transmitidas por su abuela Charlotte y Ma Agustine estos vacíos, semejantes a los olvidos que habían malformado la identidad de esta sujeto hasta casi destruirla, son llenados haciendo posible la revelación de una nueva Lisette. 


\section{RECUERDOS}

"Prohibido olvidar" asevera Paul Ricoeur en La lectura de un tiempo pasado (1999). ¿Por qué? Por varias razones que tienen que ver con el problema de la constitución de la identidad tanto colectiva como personal " $[\mathrm{p}]$ ara mantener la identidad... para mantenerla a lo largo del tiempo e incluso contra el tiempo y su poder destructor" (Ricoeur, 40). Este temido poder "destructor" al que se refiere Ricoeur también es tratado por Jelin asociándolo al temor al olvido ya que este es una amenaza a la identidad (Jelin, 19).

Debido a este temor al olvido, tanto abuela Charlotte como Ma Agustine transmiten las memorias seleccionadas a Lisette, y es en esa misma acción de transmisión de recuerdos que ellas realizan un acto de rebeldía al depositar en su sucesora esas memorias que evitarán que sus historias caigan en el temido olvido y que a su vez, ayudan a que esa búsqueda de la recuperación de la libertad perdida sea asumida por ella. A la vez, Lisette demuestra sentir mucha curiosidad por escuchar estos relatos, la cual es central a la hora de "heredar" memorias, porque, tal como lo indica Ricoeur nuestra relación con el relato comienza al momento de escucharlo: "nos cuentan historias antes de que seamos capaces de apropiarnos de la capacidad de contar y a fortiori de la de contarnos nosotros mismos" (Ricoeur, 20).

Los sueños de libertad antes mencionados no son exclusivos de la familia de Lisette, sino más bien forman parte de la identidad colectiva de toda la población esclava en Saint-Domingue e impulsan la formación de grupos de esclavos rebeldes o cimarrones que se escapan de sus amos para vivir en la clandestinidad mientras organizan una revolución que los ayuden a recuperar la libertad.

Ahora bien, a lo largo de la novela se puede apreciar que la transmisión de las memorias no es al azar, sino que responde a una organización previa que va de la mano con una intencionalidad final. Tanto abuela Charlotte como Ma Agustine seleccionan las memorias, arman los relatos y se los transmiten a Lisette en momentos claves de su vida, pese a la ansiedad que Lisette confiesa haber sentido por saber los hechos sucedidos antes de su nacimiento. Ella 
aclara que "[su] abuela se prestaba a [sus] requerimientos, salvo cuando [ella] le exigía la historia de Brigitte y la de los barracones que ella guardaba para un día especial, en el futuro" (33). De acuerdo con Jelin esto responde a una selectividad por parte de los sujetos a la hora de decidir qué contar: "el sujeto selecciona ciertos hitos, ciertas memorias que lo ponen en relación con otros" (Jelin, 25).

De los hitos seleccionados para ser relatados a Lisette, los de Abuela Charlotte pasan a ocupar el primer lugar en su memoria e identidad. Estos están contextualizados en dos etapas distintas: la primera le significó a Lisette un primer quiebre cuando aún era niña y se mostraba muy feliz porque su ama y la niña Sara le habían regalado un vestido el que ella se había colocado inmediatamente luciéndolo con orgullo, dando muestras de sentirse cómoda en su calidad de esclava, y de ser de alguna forma disfrazada con el vestido. Es entonces cuando abuela Charlotte decide contarle la dolorosa historia del tiempo de los barracones. "Te será necesaria esta herida” le dice, “[en] estos momentos en que la vida duele más que de costumbre, te darás cuenta que es a partir de ella que llegará la luz" (78). Ese recuerdo es identificado por abuela Charlotte "como el dolor vivo, en los huesos... la vergüenza a la vista" (80). Fue en ese lugar en donde ella sufrió su quiebre identitario mas fuerte ya que debido a lo angustiante de la situación y a las crueles condiciones en las que se encontraba encerrada sintió que su espíritu la había abandonado, dando cuenta de haberse sentido perdida (83).

Esta primera herida, le significó a Lisette un doloroso despertar ante su precariedad y la injusticia de su condición, por lo que decide buscar la forma de que el vestido se rasgue quedando inutilizable, a sabiendas de que sería castigada por ese "descuido".

Desde entonces Lisette alberga el deseo de salir de esta condición de esclava, comenzando así una transformación identitaria que continuó siendo alimentada por otro par de recuerdos compartidos por su abuela y que se oponían entre sí, siendo el primero una visión idílica de África, por la cual ella le transmitía una profunda nostalgia. Así lo expresó, al haber dicho a Lisette que ella "solo quier[e] tratar de recordar la alegría simple que existía antes, 
ese olor de olas, viento y arenas vivas bajo [sus] pies" (32). Este recuerdo nostálgico relacionado con la belleza de África y sus personas, se contrapone al recuerdo del traumático traslado en la Rosalía hasta el nuevo mundo: "En el barco descubrí una noche desconocida, sin cielo, sin estrellas, sin brisa, con cuerpos apretados los unos contra los otros, sin amor ni pasión, con olores y gestos desprovistos de toda intimidad, abrazos encadenados y gemidos continuos" (32).

Luego de recibir estas memorias para hacerlas propias, el tono de Lisette se vuelve pesadumbroso, lamentando tener que cargar en ella ese peso: "Siento que no podré por mucho tiempo más escapar a los recuerdos del horror, de estos recuerdos que se han hecho míos" (78).

Además de la intención de que Lisette logre trans-formar o salir de su identidad de esclava que la condenaría, está la intención de que recuerde los relatos de lo sucedido ya que por sí sola no podría recordar aquellos hechos que sellaron el destino de sus antecesoras. Así como lo señala Ricoeur "[u] no no recuerda sólo, sino con ayuda de los recuerdos del otro" (Ricoeur, 17). Al no haber vivenciado los horrores de la trata ni de la belleza de la libertad en África, deberá recordar las vivencias relatadas por otros que sí vivieron aquello y que por lo tanto no se resignan a ser esclavos.

Tras haber recibido estas primeras descargas de memorias traumáticas, se puede evidenciar en la novela que Lisette experimenta un despertar de su rebeldía y deseo de libertad, antes no evidenciado:

Sin embargo, cuando me miro en el espejo [...]. Mis ojos enormes e inquietantes abarcan todo el espacio y me hacen retroceder ante sus propios fuegos. Mis narices palpitan también como si yo no tuviera control sobre ellas y mis labios se entreabren ávidos e impacientes (100).

Luego del fallecimiento de abuela Charlotte, Lisette continúa absorbiendo los relatos de quienes la rodean, haciendo crecer en ella esa primera semilla de rebeldía que la acercaba al cimarronaje. Entre estos están los relatos de su novio, un cimarrón llamado Vincent quien le relata la tortuosa travesía de su traslado hasta Saint- Domingue. También está el de Michaud, un 
esclavo mutilado al que le falta un brazo debido a que se lo cortó para evitar tener que azotar a una esclava embarazada, y el del negro Zamor quien relata la muerte del líder cimarrón Mackandal, a quien se le atribuían poderes casi mágicos.

Pero es la última revelación entregada por Ma Agustine antes de su separación de Lisette la que sellará este proceso de trans-formación. Dicho relato estaba relacionado con la historia de quien había sido su tía abuela Brigitte, una partera Arada de la cual Lisette guarda y atesora un cordón con 70 nudos que le perteneció. En este relato Ma Agustine le cuenta a Lisette el significado de aquel cordón, cuyos nudos simbolizan a cada uno de los bebés recién nacidos a los que Brigitte sacrificó enterrándoles una espina por la mollera. La confesión de este acto por parte de Brigitte tuvo que ver con su incapacidad de hacer lo mismo con Lisette al momento de nacer, por ende ella no podía continuar haciéndolo a otros, así que se entregó a la gendarmería para ser condenada. El relato guarda una intencionalidad de nobleza por parte de Brigitte, ya que siendo ella tan amante de la libertad, no podía permitir que esos bebés crecieran condenados a vivir como esclavos (123). Así, Lisette comprende finalmente la importancia de la libertad que hasta entonces no había vivenciado, pero por la cual asume su lucha para lograr conseguir este sueño que va atado al de los nudos del cordón de su tía abuela Brigitte, de su abuela Charlotte y de Ma Agustine, de quien debe separarse para emprender el camino hacia la liberación. Este cordón de nudos no solo es la representación metafórica de aquellas vidas extintas y a la vez liberadas de la esclavitud, sino también actúa como una metáfora de las historias de esta familia de mujeres Arada, cuyas vivencias están atadas a las tradiciones y a los mismos sueños de libertad y que con ese último sacrificio también dejará atada a Lisette eternamente.

La doble intencionalidad en la transmisión de las memorias traumáticas a Lisette responde no solamente a vencer aquel poder destructor del tiempo mencionado por Ricoeur (40), o a derrotar al olvido que amenaza la identidad mencionado por Jelin (19) y que respondería a una transformación de su identidad de esclava (en el sentido básico del concepto), sino que también 
responde a la necesidad de que Lisette asuma y adopte como propios los discursos de rebeldía y lucha por la libertad que las mujeres Arada de su familia, dentro de sus capacidades siempre persiguieron, lo cual se va logrando paulatinamente a lo largo de su vida hasta que ya no le queda más que el rechazo tanto a su condición como a las personas que la han mantenido así, lo cual se evidencia cuando Lisette expresa que está “... harta de escucharlos y verlos alrededor [de ella] sin reaccionar. Una urgencia se impone en [ella] y ruge" (117). El sentimiento de identidad al que hace referencia Jelin y que ayuda a afirmar la coherencia de una persona se ve conflictuado tan profundamente en Lisette luego de recibir las memorias antes analizadas, que finalmente su identidad ya formada como esclava se trans-forma, asumiendo no solo una identidad como tal sino que haciendo propias las vivencias y los relatos de sus ancestros. "Los barracones me vuelven con sus olores de indignidad. Hago el viaje a bordo de Rosalía la Infame, siento sobre mi espalda los latigazos y las heridas. Mi piel lleva las marcas y las quemaduras, mi memoria me cuenta historias con colores de rebelión y de desesperación” (117). Esta transformación comenzó en Lisette desde el momento en que su abuela Charlotte decidió contarle sobre África y su belleza y luego sobre el horror de los barracones. Desde entonces Lisette, siendo aún niña, toma conciencia de que su condición de esclava no la define y que existe algo más allá de esa forma de vida, algo mejor que se relaciona con los recuerdos de mar y libertad que su abuela le compartió. Dicho proceso no solo se entrelaza con las imágenes de las memorias de sus antecesoras, sino que con las sensaciones que despiertan en Lisette la empatía necesaria para ansiar la libertad que le es desconocida y que ellas (sus antecesoras) ansiaban recuperar.

Lisette debe descubrir el verdadero sentido de la libertad, de acuerdo a lo que su abuela, su tía y su madre vivieron. A la vez, también debe sentir el horror de lo que les hicieron al momento de privarlas de libertad arrancándolas de su tierra natal y esclavizándolas en Saint-Domingue. De esta forma, ella puede comenzar a luchar por la liberación de su pueblo pero no sin antes escapar de su esclavitud, asumiendo todos los riesgos que ello implica.

Esta búsqueda de libertad por parte de esta "nueva" Lisette, mujer de 
herencia Arada que ya no es más una esclava sino que es una cimarrona, estará impulsada por la fuerza heredada de los relatos orales de las memorias de sus antecesoras, los que actúan como motor y núcleo de su nueva identidad trans-formada con el coraje suficiente para comenzar a luchar junto a otros cimarrones por la recuperación de la libertad y el rescate de la dignidad, organizando un rebelión histórica gracias a la cual hoy Haití es recordada como la primera Nación Negra.

\section{CONCLUSIONES}

A modo de concluir este análisis, me valgo de la siguiente pregunta extraída de Los abusos de la memoria de Tzvetan Tódorov: "Una vez restablecido el pasado, la pregunta debe ser: ¿para qué puede servir, y con qué fin?" (33). Los recuerdos de un pasado traumático que habitan en la memoria de abuela Charlotte y Ma Agustine, al ser relatados a Lisette, le producen quiebres dolorosos de los cuales "[...] quisiera poder librarse" (68). Sin embargo, este análisis da cuenta de que, aunque dolorosas, estas memorias no solo restablecen el pasado, sino que lo perpetuán en el tiempo evitando que sean olvidados. En este acto de perpetuar el pasado se encuentra la intención de asegurar un futuro más próspero para Lisette, en cuanto heredera no solo de las memorias, sino también de los sueños de libertad de sus antecesoras. Dichos sueños no eran los de ella, ya que su identidad de esclava le impedía ver más allá de las pequeñas alegrías y libertades en una vida en la cual los abusos y maltratos estaban ya asumidos como parte del diario vivir.

Entonces, en el caso de esta novela, el restablecer el pasado sirve para rescatar a una persona que ha crecido y ha desarrollado una identidad que la condena a un futuro poco auspicioso, como el de Lisette, con el fin de liberar a esta sujeto de aquel destino y alterar o trans-formar esa identidad. En torno a este concepto de trans-formación, propuesto en este análisis se da cuenta no solo del proceso de transmisión de las memorias, sino que también, se da cuenta del cómo este proceso va siendo desarrollado metódicamente, seleccionando tanto las memorias que debían ser relatadas como el tiempo 
en que debía realizarse este proceso. A raíz de esto, la protagonista va gradualmente cambiando su forma de ver el mundo, hasta llegar a liberarse de una identidad que la condenaba a ser por siempre esclava y a la vez, adoptando como propios los discursos, las vivencias, los recuerdos y la causa de sus antecesoras.

Tal como se indica en la contratapa de la versión en español esta novela (2016), a través de esta historia el lector es testigo de la lucha permanente de los cautivos por conservar su dignidad como seres humanos y a la vez por rescatar su libertad.

Vemos entonces como esta tarea de conservación y rescate está desarrollada de una manera distinta, al no estar relacionada del todo a la utilización de violencia física por parte de las personajes analizadas en este texto, sino que más bien se valen de los recursos de las memorias y de la herencia que sigue una matrilinealidad que sirve de conducto para salvar la ya mencionada dignidad y a su vez para devolver la libertad, si bien no a todas las personajes, al menos a una, la más joven, Lisette quien representa el futuro de un grupo de mujeres Aradas y que a la vez carga con las memorias de un pasado doloroso que sirve como inspiración, fuerza y fuente de la trans-formación de su identidad para aceptar la dureza de una lucha que está ad-portas de una revolución que, gracias a novelas como esta, es parte de los hitos de la historia universal, entremezclando la ficción y la realidad y que brinda un punto de vista distinto, un punto de vista femenino a un hito que será recordado como el nacimiento de la primera Nación Negra.

\section{REFERENCIAS}

Álvarez Martínez, Teresa. "Amadou Hampâté Bâ y la reconstrucción de la identidad africana a través de la oralidad", Thélème. Revista Complutense de Estudios Franceses 29/2 (2014): 265-280. Web. 23 de junio 2018. 
Carlos A. Identidad individual e identidades colectivas. Facultad de Psicología Universidad de Buenos Aires. 2005. Acta Académica. Web. 23 de junio 2018.

De Zan, Julio. "Memoria e Identidad”, TÓPICOS. Revista de Filosofía de Santa Fe (Rep. Argentina) s.v/16 (2008): 41-67. Web. 23 de junio 2018. Durosier Desrivieres, Jean. "Haïti dans le monde:Soulever le voile du silence $>$ Rosalie l'Infâme d'Evelyne Trouillot par Jean Durosier Desrivières", Collectif. Images:Haiti 2004. Web. 23 de junio 2018.

Goldstein Sepinwall, Alyssa. "If this is a Woman: Evelyne Trouillot's. The Infamous Rosalie and the Lost Stories of New-World Slavery", Fiction and Film for French historians. A Cultural Bulletin, 1/8 (2015): s.p. Web. 30 de junio 2018.

Gómez Pellón, Eloy. “Oralidad y memoria: sobre los testimonios verbales del pasado". ETNICEX s.v/4 (2012): 19-39. Web. 13 de junio 2018.

Jelin, Elizabeth. “¿De qué hablamos cuando hablamos de memorias”. Los Trabajos de la Memoria. España: Siglo Veintiuno Editores, 2002. 1737. Web. 26 de junio 2018.

Nascimento dos Santos, Daiana. El océano de fronteras invisibles: relecturas históricas sobre (¿el fin? de) la esclavitud en la novela contemporánea. Madrid, España: Editorial Verbum, 2015. Impreso.

Nascimento dos Santos, Daiana. "Rosalía la Infame (reseña)" Tabuleiro de Letras s.v/01 (2017): 169-174. eb. Web. 25 de abril 2018.

Ricouer, Paul. "Memoria individual y memoria colectiva". La lectura del tiempo pasado: Memoria y Olvido. Madrid, España: Arrecife Producciones S.L, (1999). 15-24. Impreso.

Salinas, Lilian. “Afro-feminismo y Óceanos en Rosalía la Infame de Évelyne Trouillot y El barco de ébano de Ricardo Gattini”. Coloquio Los océanos de fronteras invisibles. Universidad de Playa Ancha. (2017). Ponencia.

Tódorov, Tzvetan. Los abusos de la memoria Miguel Salazar. Barcelona: Editorial Paidós, 2000. Web. 23 de junio 2018. 
Trouillot, Évelyne. Rosalía la Infame Trad. Mercedes Bustamante. Isla Negra, Chile: Ambos editores. 2016. Impreso.

Vansina, Jean. "Tradición oral, historia oral: logros y perspectivas" Dolors Udina. Historia, Antropología y Fuentes Orales 2/37 (2007): 151-163. Web. 23 de junio 2018. 